\title{
Developmental effects of environmental light on male nuptial coloration in Lake Victoria cichlid fish
}

\author{
Daniel Shane Wright ${ }^{\text {Corresp.. }}{ }^{1}$, Emma Rietveld ${ }^{1,2}$, Martine E. Maan ${ }^{1}$ \\ ${ }^{1}$ Groningen Institute for Evolutionary Life Sciences, University of Groningen, Groningen, Netherlands \\ 2 University of Applied Sciences van Hall Larenstein, Leeuwarden, Netherlands \\ Corresponding Author: Daniel Shane Wright \\ Email address: d.s.wright@rug.nl
}

Background. Efficient communication requires that signals are well transmitted and perceived in a given environment. Natural selection therefore drives the evolution of different signals in different environments. In addition, environmental heterogeneity at small spatial or temporal scales may favour phenotypic plasticity in signaling traits, as plasticity may allow rapid adjustment of signal expression to optimize transmission. In this study, we explore signal plasticity in the nuptial coloration of Lake Victoria cichlids, Pundamilia pundamilia and Pundamilia nyererei. These two species differ in male coloration, which mediates species-assortative mating. They occur in adjacent depth ranges with different light environments. Given the close proximity of their habitats, overlapping at some locations, plasticity in male coloration could contribute to male reproductive success but interfere with reproductive isolation.

Methods. We reared P. pundamilia, P. nyererei, and their hybrids under light conditions mimicking the two depth ranges in Lake Victoria. From photographs, we quantified the nuptial coloration of males, spanning the entire visible spectrum. In experiment 1, we examined developmental colour plasticity by comparing sibling males reared in each light condition. In experiment 2 , we assessed colour plasticity in adulthood, by switching adult males between conditions and tracking coloration for 100 days.

Results. We found that nuptial colour in Pundamilia did respond plastically to our light manipulations, but only in a limited hue range. Fish that were reared in light conditions mimicking the deeper habitat were significantly greener than those in conditions mimicking shallow waters. The species-specific nuptial colours (blue and red) did not change. When moved to the opposing light condition as adults, males did not change colour.

Discussion. Our results show that species-specific nuptial colours, which are subject to strong divergent selection by female choice, are not plastic. We do find plasticity in green coloration, a response that may contribute to visual conspicuousness in darker, red-shifted light environments. These results suggest that light-environment-induced plasticity in male nuptial coloration in P. pundamilia and $P$. nyererei is limited and does not interfere with reproductive isolation. 
1 Developmental effects of environmental light on male nuptial coloration in Lake Victoria cichlid

2 fish

3 Daniel Shane Wright ${ }^{1}$, Emma Rietveld ${ }^{1,2}$, and Martine E. Maan ${ }^{1}$

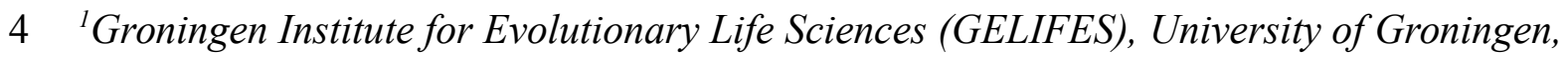

5 Groningen, The Netherlands

$6 \quad{ }^{2}$ University of Applied Sciences van Hall Larenstein, Leeuwarden, The Netherlands

7 Running title: Colour plasticity in cichlid fish

8 Corresponding author: D.S. Wright 


\section{Abstract}

13 Background. Efficient communication requires that signals are well transmitted and perceived in

14 a given environment. Natural selection therefore drives the evolution of different signals in

15 different environments. In addition, environmental heterogeneity at small spatial or temporal

16 scales may favour phenotypic plasticity in signaling traits, as plasticity may allow rapid

17 adjustment of signal expression to optimize transmission. In this study, we explore signal

18 plasticity in the nuptial coloration of Lake Victoria cichlids, Pundamilia pundamilia and

19 Pundamilia nyererei. These two species differ in male coloration, which mediates species-

20 assortative mating. They occur in adjacent depth ranges with different light environments. Given

21 the close proximity of their habitats, overlapping at some locations, plasticity in male coloration

22 could contribute to male reproductive success but interfere with reproductive isolation.

23 Methods. We reared P. pundamilia, P. nyererei, and their hybrids under light conditions

24 mimicking the two depth ranges in Lake Victoria. From photographs, we quantified the nuptial

25 coloration of males, spanning the entire visible spectrum. In experiment 1, we examined

26 developmental colour plasticity by comparing sibling males reared in each light condition. In

27 experiment 2, we assessed colour plasticity in adulthood, by switching adult males between

28 conditions and tracking coloration for 100 days.

29 Results. We found that nuptial colour in Pundamilia did respond plastically to our light

30 manipulations, but only in a limited hue range. Fish that were reared in light conditions

31 mimicking the deeper habitat were significantly greener than those in conditions mimicking

32 shallow waters. The species-specific nuptial colours (blue and red) did not change. When moved

33 to the opposing light condition as adults, males did not change colour.

34 Discussion. Our results show that species-specific nuptial colours, which are subject to strong

35 divergent selection by female choice, are not plastic. We do find plasticity in green coloration, a 
36 response that may contribute to visual conspicuousness in darker, red-shifted light environments.

37 These results suggest that light-environment-induced plasticity in male nuptial coloration in $P$.

38 pundamilia and $P$. nyererei is limited and does not interfere with reproductive isolation.

\section{Introduction}

40 Natural selection favors communication signals that maximize reception and minimize

41 degradation (Endler, 1992). Environmental heterogeneity can alter signal transmission, resulting

42 in signal variation across environments (Endler, 1990; 1992). The link between colour signals and

43 local light conditions is well established (as reviewed by: Endler \& Mappes, 2017), with many 
44 examples particularly from aquatic organisms (Seehausen et al., 1997; Boughman, 2001; Fuller,

45 2002; Cummings, 2007; Morrongiello et al., 2010; Kelley et al., 2012). However, changing

46 environmental conditions could disrupt these relationships, rendering previously conspicuous

47 signals ineffective. In such instances, flexibility in colour signaling may prove beneficial and

48 recent work has documented this capacity in a number of fish species (killifish: Fuller \& Travis,

49 2004; sticklebacks: Lewandowski \& Boughman, 2008; tilapia: Hornsby et al., 2013).

$50 \quad$ Plasticity in mating signals can have major evolutionary consequences. In particular,

51 when signals mediate reproductive isolation, plastic changes in response to environmental

52 variation could affect the extent of assortative mating, resulting in gene flow that may inhibit or

53 even reverse species differentiation. Conversely, plasticity in mating signals can also provide a

54 starting point for species divergence, as has been suggested for song learning in birds (Lachlan \&

55 Servedio, 2004; Mason et al., 2017). Here, we examine how changes in the local light

56 environment affect colour signaling in Lake Victoria cichlids.

57 In teleost fish, coloration derives from cells specialized for the storage and synthesis of

58 light-absorbing and light-reflecting structures (Sugimoto, 2002; Leclercq et al., 2010). These

59 cells, chromatophores, are distributed throughout the integument and are responsible for the wide

60 variety of colours and patterns present in fish (Leclercq et al., 2010). In addition to genetic

61 variation, fish coloration may change plastically in response to a multitude of factors (e.g.

62 nutritional state, social interactions, local conditions, Leclercq et al., 2010). Short-term

63 (physiological) colour change - e.g. in signaling social state (Maan \& Sefc, 2013) - involves

64 hormonal and neurological processes that affect the density of pigments within existing

65 chromatophores (Sugimoto, 2002). Over longer time scales (e.g. across development), fish can

66 undergo colour change by the generation of new and/or the death of existing chromatophores

67 (Sugimoto, 2002). Both processes are likely to play a role in the adjustment of colour signals to

68 changing environmental conditions. 
70 Witte, 1985) are two closely related, rock-dwelling species of cichlid fish that co-occur at rocky

71 islands in southern Lake Victoria (Seehausen, 1996). They are anatomically very similar and

72 behave as biological species in clear waters but hybridize in more turbid waters (Seehausen et al.,

73 1997). Males of the two species are distinguished by their nuptial coloration; P. pundamilia males

74 are blue/grey, whereas $P$. nyererei males are yellow with a crimson-red dorsum. Females of both

75 species are yellow/grey in colour (Seehausen, 1996; van Alphen et al., 2004). Although

76 sympatric, the two species tend to have different depth distributions: P. pundamila is found in

77 shallower waters while P. nyererei extends to greater depths. High turbidity in Lake Victoria

78 results in a shift of the light spectrum toward longer wavelengths with increasing depth and, as

79 such, P. nyererei inhabits an environment largely devoid of short-wavelength light (Maan et al.,

80 2006; Seehausen et al., 2008; Castillo Cajas et al., 2012). Previous work has found female

81 preferences for conspecific male nuptial colouration in both species (Seehausen \& van Alphen,

82 1998; Haesler \& Seehausen, 2005; Stelkens et al., 2008; Selz et al., 2014) and the differences in

83 male colour are necessary and sufficient for reproductive isolation (Selz et al., 2014). However,

84 we have recently observed that female preferences are influenced by the light environment

85 experienced during development (Wright et al., 2017). When reared in broad-spectrum light,

86 characteristic of the $P$. pundamila habitat, females more often preferred the blue P. pundamilia

87 males while females reared in red-shifted light, characteristic of P. nyererei habitats, tended to

88 prefer the red P. nyererei males (Wright et al., 2017). Given the role of the light environment in

89 female preference determination, a question then follows: how does the local light environment

90 affect the expression of male nuptial colour?

91 Observations from wild populations suggest that the local light environment does

92 influence coloration, as $P$. nyererei from turbid (long wavelength-shifted) and clear water (broad-

93 spectrum) locations differ in redness (Maan et al., 2010; Castillo Cajas et al., 2012). Anal fin 
94 spots, characteristic yellow-orange ovoid markings on the anal fins of Haplochromine cichlids

95 (Goldschmidt, 1991; Maan \& Sefc, 2013), also co-vary with environmental light. Goldschmidt

96 (1991) reported that Lake Victoria species inhabiting darker environments have larger anal fin

97 spots and, more recently, Theis and colleagues reported that $A$. burtoni from Lake Tanganyika

98 have less intensely coloured spots than populations from turbid rivers (Theis et al., 2017). These

99 patterns are implicitly attributed to genetic variation, but phenotypic plasticity may also play a

100 role. With the close proximity of P. pundamilia and P. nyererei habitats (a few meters to tens of

101 meters, with overlapping distributions at several locations: Seehausen et al., 2008) and the fact

102 that light conditions can fluctuate between seasons and due to weather (wind/rain), selection may

103 favour some degree of plasticity in male colour expression. In fact, plasticity in cichlid colour has

104 been documented: Nile tilapia increased short-wavelength body reflectance when reared under

105 red-shifted light (Hornsby et al., 2013) and both South American (Kop \& Durmaz, 2008) and

106 African cichlids (McNeil et al., 2016) changed colour in response to carotenoid availability in the

107 diet. Diet-induced colour changes have also been observed in Pundamilia (DSW \& MEM - Pers.

108 Obs.), but common-garden and breeding experiments suggest strong heritability and low

109 plasticity of the interspecific colour differences (Magalhaes et al., 2009; Magalhaes \& Seehausen,

110 2010).

111 In this study, we experimentally manipulated environmental light and tested its effect on

112 male nuptial colour expression. By rearing sibling males under light conditions mimicking

113 shallow and deep habitats of Lake Victoria, we were able to ask: does the light environment

114 experienced during ontogeny affect the development of nuptial coloration in Pundamilia? Given

115 that blue colour is an ineffective signal in deep-water light conditions (lacking short

116 wavelengths), we predicted that deep-reared fish might exhibit more long-wavelength reflecting

117 coloration. We also moved a sub-set of males between rearing environments during adulthood,

118 allowing us to test the effect of sudden environmental change and ask: do adult Pundamilia 
119 males adjust their colour in response to changing conditions? Again, we predicted that fish

120 moved to deep light would express more long-wavelength reflecting colours.

\section{Methods}

122 Fish rearing \& maintenance - Offspring of wild caught $P$. pundamilia and $P$. nyererei, collected at

123 Python Islands in the Mwanza Gulf of Lake Victoria (-2.6237, 32.8567 in 2010 \& 2014), were

124 reared in light conditions mimicking those in shallow and deep waters at Python Islands (as in:

125 Maan et al., 2017; Wright et al., 2017). Lab-bred lines (hybrid and non-hybrid) were created

126 opportunistically as reciprocal crosses, with 18 dams and 14 sires. Hybridization does occur with

127 low frequency at Python Islands (Seehausen et al., 2008) and can be accomplished in the lab by

128 housing females with heterospecific males. Fourteen F1 crosses (wild parents: 6 P. nye $x$ P. nye; 4

129 P. pun $x$ P. pun; 1 P. nye $x$ P. pun; 3 P. pun $x$ P. nye) and five F2 crosses (lab-bred parents: 1 P. nye

$130 x$ P.pun; 4 hybrid $\mathrm{x}$ hybrid) resulted in a test population of 58 males from 19 families (family

131 details provided in table S1). We included F2 fish due to low availability of F1 hybrids.

$132 \quad$ Pundamilia are maternal mouth brooders; fertilized eggs were removed from brooding

133 females approximately 6 days after spawning (mean \pm se: $6.3 \pm 0.5$ days post-fertilization; eggs

134 hatch at about 5-6 dpf) and split evenly between light conditions. Upon reaching maturity, males

135 displaying nuptial coloration were removed from family groups, PIT tagged (Passive Integrated

136 Transponders, from Biomark, Idaho, USA, and Dorset Identification, Aalten, The Netherlands),

137 and housed individually, separated by transparent, plastic dividers. All males were housed next to

138 a randomly assigned male, with either 1 or 2 neighbour males (depending on location within the

139 tank). Neighboring fish were the same for the duration of each sampling period (more details

140 below). Fish were maintained at $25 \pm 1^{\circ} \mathrm{C}$ on a $12 \mathrm{~L}: 12 \mathrm{D}$ light cycle and fed daily a mixture of

141 commercial cichlid flakes and pellets and frozen food (artemia, krill, spirulina, black and red 
142 mosquito larvae). This study was conducted under the approval of the Institutional Animal Care

143 and Use Committee of the University of Groningen (DEC 6205B; CCD 105002016464). The

144 Tanzania Commission for Science and Technology (COSTECH) approved field permits for the

145 collection of wild fish (2010-100-NA-2010-53 \& 2013-253-NA-2014-177).

146 Experimental light conditions - Experimental light conditions were created to mimic the natural

147 light environments of $P$. pundamilia and $P$. nyererei at Python Islands, Lake Victoria (described in 148 greater detail: Maan et al., 2017; Wright et al., 2017). Species-specific light spectra were

149 simulated in the laboratory (Fig. S1) by halogen light bulbs filtered with a green light filter (LEE 150 \#243, Andover, UK). In the 'shallow' condition, mimicking P. pundamilia habitat, the spectrum

151 was blue- supplemented with Paulmann 88090 compact fluorescent $15 \mathrm{~W}$ bulbs. In the 'deep

152 condition', mimicking $P$. nyererei habitat, short wavelength light was reduced by adding a yellow

153 light filter (LEE \#015). The light intensity differences between depth ranges in Lake Victoria are

154 variable and can change rapidly depending on weather and sun angle (as much as 1000-fold in

155 sun vs. cloud cover); the mean ( \pm se) light intensity in the deep environment (measured in 2010)

156 was $34.15 \pm 3.59 \%$ of that in the shallow environment (Fig. S1). Our experimental light

157 conditions were designed to mimic in particular the spectral differences between depths and only

158 partly recreated the intensity difference (the deep condition had a light intensity of $\sim 70 \%$ of that

159 of the shallow condition).

160 Experiment 1: developmental colour plasticity - Males reared under experimental light conditions

161 from birth were photographed repeatedly (3 times each) in adulthood and assessed for body/fin

162 coloration (details below). In total, we examined 29 pairs of brothers (mean age \pm se at first

163 sample: $689.9 \pm 67$ days; Pundamilia reach sexual maturity at $\sim 240$ days), 29 from each light

164 condition $(2 \times 10$ P. pun, $2 \times 9$ P. nye, $2 \times 10$ hybrids, table S1). Males were sampled from August 
165 - October 2016, with a mean ( \pm se) of $13.25 \pm 0.83$ days between samples. Neighbour males

166 (those housed next to test fish) were maintained for the duration of the sampling period.

167 Experiment 2: colour plasticity in adulthood - Following experiment 1, a subset of fish (table S2)

168 was switched to the opposing light condition (mean age \pm se when switched: $643.47 \pm 50.61$

169 days; sexual maturity is 240 days) and colour tracked for 100 days. Each fish was photographed

17011 times over the 100-day period: $1,2,3,4,7,10,14,18,46,73,100$ days after switching. We

171 switched 24 males, 12 from each light condition ( $2 \times 4$ P. pun, $2 \times 4$ P. nye, 2 x 4 hybrid $)$. As a

172 control, we also tracked 18 males (9 from each light condition: $2 \times 3$ P. pun, 2 × 3 P. nye, 2 × 3

173 hybrid) that remained in their original rearing light, but were moved to different aquaria (thus,

174 both experimental and control fish had new 'neighbour' males). All fish, control and

175 experimental, were photographed at the same 11 time points (in addition to the 3 photographs

176 from experiment 1). The experiment was conducted in two rounds: October 2016 - January 2017

177 (24 fish moved: 6 experimental \& 6 control from each light condition) and December 2016 -

178 March 2017 (18 fish moved: 6 experimental \& 3 control from each light condition).

179 Photography - All males were photographed under standardized conditions with a Nikon D5000

180 camera and a Nikon AF-S NIKKOR18-200mm ED VR II lens. Fish were removed from their

181 housing tank and transferred to a glass cuvette, placed within a $62.5 \mathrm{~cm} \mathrm{x} 62.5 \mathrm{~cm}$ domed

182 photography tent (Kaiser Light Tent Dome-Studio). This tent ensured equal illumination for all

183 photos provided by an external flash (Nikon Speedlight SB-600) set outside of the tent. To ensure 184 consistency of colour extracted from digital images (Stevens et al., 2007), all photos contained a

185 grey and white standard attached to the front of the cuvette (Kodak colour separation guide),

186 were taken with the same settings (ISO: 200; aperture: F9; exposure: 1/200; flash intensity: 1/8), 187 and saved in RAW format. 
188 Colour analysis - In Adobe Photoshop CS4, we adjusted the white balance and removed the

189 background from each photo, keeping the entire fish (except the eye and pelvic fins). Each fish

190 was then cropped into separate sections (body excluding fins, dorsal fin, caudal fin, anal fin, anal

191 fin spots) and saved as individual images. Each section was analyzed for coloration using ImageJ

192 (https://imagej.nih.gov/ij/), following the same procedure as detailed in Selz et al. (2016). We

193 defined specific colours by their individual components of hue, saturation, and brightness to

194 cover the entire hue range, resulting in a measure of the number of pixels that met the criteria for

195 red, orange, yellow, green, blue, magenta, violet, and black for each section (colour parameter

196 details provided in table S3).

197 Brightness - We also measured the mean brightness of fish. Using Photoshop, we recorded the 198 luminosity of 'whole fish' and 'anal fin spot' images, calculated from RGB values as: 0.3R + 199 0.59G + 0.11B (defined as brightness in: Bockstein, 1986). The weighting factors used by

200 Photoshop $(0.3,0.59,0.11)$ are based on human perception and should be similar to the

201 trichromatic visual system of Pundamilia (Carleton et al., 2005). We measured the mean

202 brightness of all fish used in experiment 1 and from three time points in experiment 2 (days 1, 10, 203 100).

\section{Statistical analysis}

205 Colour scores - Colour scores were defined as a percentage of coverage: the number of pixels in

206 each colour category divided by the total number of pixels in the section. We used principal

207 component analysis (PCA) on the correlation matrix of all eight colour scores to obtain

208 composite variables of coloration (separate PCA was performed for each section - loading 
209 matrices in table S4). In experiment 1, we examined PC1-PC4, as PC5 accounted for $<10 \%$ of

210 the variance in all analyses (mean cumulative variance $=82.5 \%$; mean across all sections). For all

211 analyses, we first assessed 'whole fish' images (minus eye and pelvic fins), followed by

212 examination of each individual section (body, dorsal fin, caudal fin, anal fin, anal fin spots). Anal

213 fin spots contained only red, orange, and yellow, thus PC's were based on only those colour

214 scores (and consequently, only PC1 \& PC2 were used in analyses, 96.8\% cumulative variance, 215 table S4).

216 In experiment 2, we first calculated baseline mean PC scores per fish using the repeated

217 samples from experiment 1. At each time point after the switch, we then assessed deviation from

218 the mean, calculated as: PC score - mean baseline PC score. Measuring the deviations from

219 individual means allowed us to track the direction of colour change for each fish, independent of

220 individual variation in baseline. Once again, PC scores were calculated for each body part

221 independently and we used only PC1-PC4 (mean cumulative variance $=79.8 \%$; loading matrices 222 in table S5).

223 Experiment 1: developmental colour plasticity - Using linear mixed modeling (lmer function in

224 the lme4 package, Bates et al., 2013) in R (v3.3.2; R Development Core Team), we tested PC's

225 for the influence (and interactions) of: rearing light (shallow vs. deep), species (P. pun, P. nye, or

226 hybrid), and body size (standard length, SL). Random effects included fish identity, parental

227 identity, aquaria number, and position within aquaria to account for: 1) repeated sampling, 2)

228 shared parentage among fish (table S1), 3) location of aquaria within the housing facility, 4)

229 number of neighboring males (1 or 2). The optimal random effect structure of models was

230 determined by AIC comparison (Sakamoto et al., 1986) and the significance of fixed effect

231 parameters was determined by likelihood ratio tests (LRT) via the drop1 function. Minimum

232 adequate statistical models (MAM) were selected using statistical significance (Crawley, 2002; 
233 Nakagawa \& Cuthill, 2007). We then used the KRmodcomp - pbkrtest package (Halekoh \&

234 Højsgaard, 2014) to test the MAM against a model lacking the significant parameter(s), which

235 allowed us to obtain the estimated effect size of fixed effect parameters under the Kenward-Roger

236 (KR) approximation (Kenward \& Roger, 1997; Kenward \& Roger, 2009). In the case of more

237 than two categories per fixed effect parameter (i.e. species), we used post hoc Tukey (glht -

238 multcomp package: Hothorn et al., 2008) to obtain parameter estimates.

239 Anal fin spot number - Following Albertson et al. (2014), the number of anal fin spots was

240 counted as the sum of complete (1.0 each) and incomplete ( 0.5 each) spots for each fish

241 (incomplete fin spots occur along the perimeter of the anal fin, often becoming complete with

242 age/growth). Total spot number was compared among species, rearing light, and SL using the

243 glmer.nb function in lme4 (Bates et al., 2013). Random effects were the same as above and

244 reduction to MAM followed the same procedure. As KRmodcomp is unavailable for glmer.nb,

245 final parameter estimates are reported from LRT via the dropl function (Ripley et al., 2015).

246 Experiment 2: colour plasticity in adulthood - Using lme in package nlme (Pinheiro et al., 2014),

247 we tracked fish coloration change over time, testing the influence (and interactions) of: species,

248 treatment (rearing environment + 'switched' environment) and date (of sampling). We used lme

249 because it allows specification of the optimal autocorrelation structure, as autocorrelation is

250 common in longitudinal data (Crawley, 2007; Zuur et al., 2009). Random effects were the same

251 as above, but with an additional random slope/random intercept term for date and fish identity

252 ( date | fish identity) to account for variability in the nature of colour change over time between

253 individual fish. For simplification to MAM, models were fit with maximum likelihood (ML) and

254 selected for statistical significance (Crawley, 2002; Nakagawa \& Cuthill, 2007) by LRT using

255 drop1. Final models were refit with restricted maximum likelihood (REML) and fixed effect 
256 parameters of MAM reported from the anova function. As above, we used post hoc Tukey

257 (Hothorn et al., 2008) to obtain estimates for more than two categories per parameter.

\section{Results}

\section{Light-independent, interspecific differences}

260 Coloration - To estimate the overall 'colourfulness' of fish, we calculated the sum of all

261 measured colour scores for each male (whole body). Species did not differ in colourfulness $(\mathrm{P}=$

262 0.29), nor did they differ in colours not defined by our colour parameters (calculated as: $100-$

263 sum of all measured colours; $\mathrm{P}=0.29$ ).

264 There was a significant difference between species $\left(F_{2,55.00}=13.40, P<0.001\right.$, Fig. 1a) in

265 whole fish PC1 (positive loading yellow/orange). Tukey post hoc revealed that P. nyererei scored

266 significantly lower than P.pundamilia $(\mathrm{Z}=-5.39, \mathrm{P}<0.001)$ and hybrids $(\mathrm{Z}=-3.76, \mathrm{P}<0.001)$.

267 P. pundamilia was highest but did not differ significantly from hybrids $(\mathrm{P}=0.47)$. There were

268 tendencies for differences among species for whole fish PC3 $\left(\mathrm{F}_{2,12.33}=3.81, \mathrm{P}=0.051\right.$, Fig. 1c)

269 and PC4 $\left(\mathrm{F}_{2,55.00}=2.49, \mathrm{P}=0.09\right.$, Fig. 1d). PC3 loaded positively with red/orange, with $P$.

270 nyererei scoring highest and differing significantly from $P$. pundamilia $(\mathrm{Z}=2.58, \mathrm{P}=0.026)$, but

271 not quite so from hybrids $(\mathrm{Z}=2.08, \mathrm{P}=0.09)$. PC4 had a strong, positive association with violet

272 and followed the same general pattern as PC3 (P. nyererei highest). There were no significant

273 differences for whole fish PC2 ( $\mathrm{P}=0.55$; positive association with green/blue, Fig. 1b). Species

274 differences for each body area separately are presented in Fig. S2. We saw a slight difference in

275 mean brightness $\left(\mathrm{F}_{2,55.00}=2.5, \mathrm{P}=0.08\right)$ : P. nyererei was lowest, differing somewhat from $P$.

276 pundamilia $(\mathrm{Z}=2.3, \mathrm{P}=0.053)$, while other comparisons were non-significant $(\mathrm{P}>0.18)$. 
277 Anal fin spots - Anal fin spot coloration did not differ among species $(\mathrm{PC} 1: \mathrm{P}=0.25 ; \mathrm{PC} 2: \mathrm{P}=$

$2780.15)$ but the number of anal fin spots differed significantly $(\mathrm{df}=2, \mathrm{LRT}=8.50, \mathrm{P}=0.014$; Fig.

279 2). $P$. nyererei had significantly more spots than $P$. pundamilia $(\mathrm{Z}=2.85, \mathrm{P}=0.017)$, while

280 hybrids were intermediate and did not differ from either parental species $(\mathrm{P}>0.18)$. A statistical

281 trend indicated that anal fin spot brightness also varied between species $\left(\mathrm{F}_{2,55.00}=2.56, \mathrm{P}=0.08\right)$ :

282 P. nyererei had the brightest spots, differing slightly from hybrids $(\mathrm{Z}=2.17, \mathrm{P}=0.07)$ but not

283 from P. Pundamilia $(\mathrm{P}=0.81)$. The total surface area $(\mathrm{P}=0.10)$ or the size of the largest anal fin

284 spot did not differ among species $(\mathrm{P}=0.19)$.

285 Body size - Species differed significantly in $\mathrm{SL}\left(\mathrm{F}_{2,55}=8.06, \mathrm{P}=0.008\right)$ : hybrids were larger than

286 both P. nyererei $(\mathrm{t}=3.50, \mathrm{P}=0.002)$ and . pundamilia $(\mathrm{t}=3.42, \mathrm{P}=0.003)$ but the parental

287 species did not differ $(\mathrm{P}=0.98)$. There was no relationship between SL and overall fish

288 colorfulness $(\mathrm{P}=0.43)$ or anal fin spot coloration $(\mathrm{P}>0.37)$. We found significant, negative

289 relationships between $\mathrm{SL}$ and whole fish $\mathrm{PC} 4\left(\mathrm{~F}_{1,56.00}=4.95, \mathrm{P}=0.03\right.$; strong, positive association

290 with violet), caudal fin $\mathrm{PC} 1\left(\mathrm{~F}_{1,56.00}=13.63, \mathrm{P}<0.001\right.$; positive with yellow/orange/violet and

291 negative with red/black), and caudal fin PC4 $\left(\mathrm{F}_{1,56.00}=29.53, \mathrm{P}<0.001\right.$; strong, positive loading

292 with violet). Collectively, these results show that smaller fish expressed higher violet colour

293 scores and were generally brighter: brightness was significantly negatively related with SL $\left(\mathrm{F}_{1}\right.$,

$29456.00=11.31, \mathrm{P}=0.001)$. Violet covered a relatively small proportion of the fish $(<1 \%$ in $P$.

295 pundamilia \& hybrids, $2 \%$ in $P$. nyererei), while black, whose PC loadings were in the opposite

296 direction of violet (see Table S4), covered a larger area ( $\sim 16 \%$ in $P$. nyererei \& hybrids, $\sim 7 \%$ in $P$.

297 pundamilia). Individual colour analyses revealed a trend for a positive association between SL

298 and black $\left(\mathrm{F}_{1,50.43}=2.99, \mathrm{P}=0.08\right)$, suggesting that larger fish were generally blacker and less

299 bright. Larger fish also had higher total anal fin spot surface area $\left(\mathrm{F}_{1,56.00}=11.51, \mathrm{P}=0.001\right)$. 


\section{Experiment 1: developmental colour plasticity}

301 No difference in total coloration - Deep- vs. shallow-reared fish did not differ in overall

302 colourfulness or in areas not defined by our colour parameters ( $\mathrm{P}>0.5$ for both).

303 Increased green in deep light - We predicted that deep-reared fish would increase long-

304 wavelength reflecting coloration, which would imply lower PC1 scores and higher PC3/PC4

305 scores. However, this was not the case (PC1 \& PC3/PC4 scores did not differ between rearing

306 environments, $\mathrm{P}>0.59$ for all). Instead, we found that, independent of species, deep-reared fish

307 had significantly higher PC2 scores $\left(F_{1,40.07}=9.08, P=0.004\right.$, Fig. 3a), which could be attributed

308 to body PC2 $\left(\mathrm{F}_{1,40.12}=4.89, \mathrm{P}=0.03\right.$, Fig. $\left.3 \mathrm{~b}\right)$ and, to a lesser extent, caudal fin $\mathrm{PC} 2\left(\mathrm{~F}_{1,30.93}=\right.$

$3093.18, \mathrm{P}=0.083$, Fig. 3c). The strongest positive PC2 loadings were with green/blue (body PC2

310 also loaded positively with red/magenta; caudal fin PC2 with red/violet). We also found a non-

311 significant trend for deep-reared fish to have lower PC4 body scores $\left(\mathrm{F}_{1,56.00}=3.77, \mathrm{P}=0.057\right.$;

312 PC4 loaded negatively for green/black), again indicating increased green colour in deep light.

313 Separate analyses of each colour category confirmed this pattern; only green differed between

314 rearing conditions $\left(\mathrm{F}_{1,40.11}=11.36, \mathrm{P}=0.001\right.$, Fig. $\left.4 \mathrm{a}\right)$. This difference was species-independent,

315 observed in P. pundamilia, P. nyererei, and hybrids (see Fig. S3). Increased green in deep-reared

316 fish did not correspond to higher brightness $(\mathrm{P}=0.43)$. For species-specific coloration in

317 each light environment, see Fig. S4.

318 Short vs. long-wavelength colour expression - To test our prediction that deep-reared fish will

319 generally express more long-wavelength colours, we split the measured colours into two

320 categories: reflecting shorter-wavelengths (violet, blue, green) and reflecting longer-wavelengths

321 (yellow, orange, red). This analysis excluded magenta (which has both red and blue components)

322 and black. Contrary to our prediction, deep-reared fish expressed significantly higher amounts of 
323 short-wavelength colours $\left(\mathrm{F}_{1,40.12}=7.40, \mathrm{P}=0.009\right)$, while long-wavelength colour expression

324 did not differ $(\mathrm{P}=0.7)$.

325 Anal fin spots - Rearing light had no effect on anal fin spot coloration (PC1: $\mathrm{P}=0.30 ; \mathrm{PC} 2: \mathrm{P}=$

$3260.17)$, brightness $(\mathrm{P}=0.49)$, the number of spots $(\mathrm{P}=0.37)$, total surface area $(\mathrm{P}=0.98)$, or size

327 of the largest spot $(\mathrm{P}=0.30)$.

\section{Experiment 2: colour plasticity in adulthood}

329 Little effect of treatment - As seen in figure 5, fish that were moved between light conditions did

330 not display consistent changes in coloration compared to baseline or to controls. For whole fish

331 PC3 and for body PC4, we found significant three-way interactions between treatment, species,

332 and date $\left(\mathrm{F}_{6,408}=2.33, \mathrm{P}=0.031\right.$ and $\left.\mathrm{F}_{6,408}=3.34, \mathrm{P}=0.003\right)$ but treatment did not cause

333 consistent changes in coloration (Fig. S5/S6). Treatment had no effect on mean fish brightness (P

$334=0.41)$ or anal fin spot coloration/brightness $(\mathrm{P}>0.26)$. We found a significant effect of 'date' in

335 nearly all analyses (table S6), indicating that both experimental and control fish continued to

336 change colour over the 100-day sampling period. Thus, the lack of treatment effect was not due to

337 fish colour being inflexible in adulthood.

\section{Discussion}

339 Local conditions impact the effectiveness of communication signals (Endler, 1990; 1992) and can

340 be greatly disrupted by environmental variation. Plasticity in signal production may be one

341 mechanism to cope with changing conditions. Here, we tested for light-induced plastic changes in

342 the nuptial coloration of Pundamilia pundamilia and Pundamilia nyererei by rearing sibling 
343 males in environments mimicking deep- and shallow-water habitats of Lake Victoria. We found

344 little evidence for developmental colour plasticity.

\section{Limited colour plasticity}

346 P. pundamilia and $P$. nyererei are naturally depth segregated and occupy different light

347 environments in Lake Victoria (Maan et al., 2006; Seehausen et al., 2008; Castillo Cajas et al.,

348 2012). Given the close proximity of the two habitats (overlapping at some locations), selection

349 might favour some level of flexibility in colour expression to cope with different signaling

350 environments. Previous studies in other fish species have shown light-induced plasticity in

351 coloration (Fuller \& Travis, 2004; Lewandowski \& Boughman, 2008; Hornsby et al., 2013).

352 Contrary to our predictions, we found that deep-reared fish did not express more long-wavelength

353 reflecting coloration. Instead, deep-reared fish were greener. Our light manipulations did not

354 affect the male colours that most clearly differentiate the two species (blue/red). Additionally,

355 males switched between light environments as adults showed little colour change. We propose

356 two explanations for the lack of plasticity in nuptial coloration.

357 The first is that nuptial coloration in Pundamilia is under strong genetic control. Previous

358 work has shown that species-specific coloration in Pundamilia is heritable (Magalhaes et al.,

359 2009) and likely controlled by a small number of loci (Magalhaes \& Seehausen, 2010). Common

360 garden experiments by Magalhaes et al. (2009) found higher plasticity in morphological traits

361 than in male colour scores but fish were reared under standard aquarium lighting (for light spectra

362 comparison, see Fig. S1). We observed light-induced plasticity in green, which, unlike other male

363 colours, is not subject to strong divergent selection by female choice (as demonstrated by: Selz et

$364 a l ., 2014)$ and perhaps less rigidly controlled (see below).

365 A second potential explanation for our results is that our light manipulations mimicked

366 natural spectral variation, but only partially reproduced variation in light intensity. The difference 
367 in light intensity between the deep and shallow habitat in Lake Victoria is variable, but the deep

368 habitat is consistently darker. While spectral differences have repeatedly been shown to correlate

369 with numerous Pundamilia characteristics, light intensity may also play a role. Future studies

370 could examine this by manipulating light intensity independent of spectral composition.

371 Finally, our sample size was modest (9-10 and 4 individuals per group in experiment 1

372 and 2, respectively). However, while increasing the sample size might increase statistical support

373 for some of our results, we found relatively small effect sizes and these would likely not be

374 affected. Thus, we expect that larger sample sizes would not change the main conclusions

375 presented here.

\section{Increased green in deep}

377 Males reared in the deep light environment were significantly greener than shallow-reared fish.

378 Our light manipulations differed primarily in short-wavelength availability and green

379 wavelengths were abundant in both conditions (Fig. 4b). If plasticity in the species-specific male

380 colours (blue/red) is limited, then increased green reflectance in darker conditions might be an

381 alternative solution to increase visibility. To test this, we measured mean brightness of fish reared

382 in both conditions. We found no difference in brightness between rearing environments, nor did

383 brightness change when fish were switched in adulthood. This would suggest that differences in

384 green colour do not contribute to increased visibility. However, these results are based on

385 measurements of RGB values from photographs and may not properly capture contrast and

386 perception in a specific light environment. Green covers a relatively small proportion of the fish

387 ( $\sim 6 \%$ in deep light) and is not concentrated in a specific area of the body (unlike the red dorsum

388 of $P$. nyererei, for example), making reflectance spectrometry difficult. Moreover, changes in

389 green coloration coincided with non-significant changes in multiple other colours (see Fig. 4a),

390 all of which may contribute to detectability. 
392 of shorter-wavelength colours, while longer-wavelength colours did not differ. These findings

393 resemble those of Hornsby et al. (2013), who reared Nile tilapia in an environment lacking short-

394 wavelength light and found higher expression of short-wavelength colours. The authors

395 suggested that this response might be adaptive as it increases the contrast against the short-

396 wavelength-poor background (Lythgoe, 1968; Hornsby et al., 2013). Possibly, this response

397 represents a common strategy in cichlid fish.

\section{Anal fin spots}

399 Haplochromine cichlids possess carotenoid-dependent, yellow-orange, circular spots on their anal 400 fins (Goldschmidt, 1991; Tobler, 2006). While the adaptive significance of these spots is debated

401 (Maan \& Sefc, 2013), previous studies have documented environment-contingent spot coloration 402 in a number of species (Goldschmidt, 1991; Castillo Cajas et al., 2012; Theis et al., 2017). We 403 examined the coloration, brightness, number and size of the anal fin spots and found that none of 404 these measures were influenced by our light manipulations. However, we did find species 405 differences: P. nyererei had the highest number of anal fin spots and the spots were generally 406 brighter. Given that P. nyererei naturally occurs in the deep, short-wavelength poor habitat, this 407 follows the general patterns presented by Goldschmidt (1991) and Theis et al. (2017); the 408 exception being that $P$. nyererei in our study did not exhibit larger fin spots. The absence of 409 colour differences in the anal fin spots of P. pundamilia and P. nyererei is consistent with earlier 410 results based on reflectance spectrometry of wild fish (Castillo Cajas et al., 2012).

\section{Implications for species isolation}

412 P. pundamilia and P. nyererei differ in nuptial coloration and colour has been shown to co-vary 413 with light conditions (Maan et al., 2010; Castillo Cajas et al., 2012). Females display divergent 
414 preferences for conspecific male colour (Seehausen \& van Alphen, 1998; Haesler \& Seehausen,

415 2005; Stelkens et al., 2008; Selz et al., 2014) and these preferences are key to species isolation

416 (Selz et al., 2014). Differences in visual system characteristics (Carleton et al., 2005; Maan et al.,

417 2006; Seehausen et al., 2008) correspond to differences in light environments, male coloration,

418 and female preferences, suggesting a role for divergent sensory drive in speciation (Maan \&

419 Seehausen, 2010). Recently, we have shown that the same light manipulations that we used here

420 significantly influenced female mate preference, potentially interfering with reproductive

421 isolation (shallow-reared females preferred blue males, while deep-reared females favoured red

422 males (Wright et al., 2017)). Plasticity in male colour expression could weaken the linkage

423 disequilibrium between colour and preference even further. However, we find little evidence for

424 such plasticity here, suggesting that blue and red are likely under strong genetic control. This may

425 preserve reproductive isolation between populations inhabiting adjacent visual environments. In

426 contrast, the plastic response in green coloration may aid in overall detectability of males,

427 without interfering with species-assortative mating decisions that rely on interaction at closer 428 range.

\section{Conclusions}

430 Our results show that the nuptial coloration of $P$. pundamilia and $P$. nyererei is largely not plastic.

431 Rearing fish in two distinct light conditions mimicking those at different depth ranges in Lake

432 Victoria had little effect on species-specific colour, which is consistent with existing evidence for

433 strong divergent selection on male coloration in this species pair. We did find evidence for light-

434 induced plasticity in green coloration, possibly promoting male detectability but not interfering

435 with species-assortative mating. Taken together, these results provide continued support for the

436 role of the local light environment in species isolation in Pundamilia. Reproductive isolation may 
437 be affected by environmental change but as this study shows, rapid changes in sexually selected

438 colour signals are unlikely.

\section{Acknowledgements}

440 We acknowledge the Tanzanian Commission for Science and Technology for research permission

441 and the Tanzanian Fisheries Research Institute for hospitality and facilities. We thank Mhoja

442 Kayeba, Mohamed Haluna, Erwin Ripmeester, Oliver Selz, Jacco van Rijssel, Florian Moser, and

443 Joana Meier for help with fish collections and Sjoerd Veenstra and Brendan Verbeek for taking

444 care of the fish in the laboratory. Oliver Selz also provided helpful tips for completing the colour

445 analyses. Demi Damstra and Thomas Scheffers aided in designing and conducting pilot

446 experiments, Titus Hielkema and Silke Scheper helped with image preparation and colour

447 assessment, and Roy Meijer assisted during photography sessions.

\section{References}

449 Albertson, R.C., Powder, K.E., Hu, Y., Coyle, K.P., Roberts, R.B. \& Parsons, K.J. 2014. Genetic basis of

450 continuous variation in the levels and modular inheritance of pigmentation in cichlid fishes. Mol. Ecol. 23:

$451 \quad 5135-5150$.

452 Bates, D., Maechler, M., Bolker, B. \& Walker, S. 2013. Lme4: Linear mixed-effects models using eigen

453 and S4. $R$ package version 1.7.

454 Bockstein, I.M. 1986. Color equalization method and its application to color image processing. JOSA A 3: $455 \quad 735-737$. 
456 Boughman, J.W. 2001. Divergent sexual selection enhances reproductive isolation in sticklebacks. Nature

457 411: 944-948.

458 Carleton, K.L., Parry, J.W., Bowmaker, J.K., Hunt, D.M. \& Seehausen, O. 2005. Colour vision and

459 speciation in lake victoria cichlids of the genus pundamilia. Mol. Ecol. 14: 4341-4353.

460 Castillo Cajas, R.F., Selz, O.M., Ripmeester, E.A., Seehausen, O. \& Maan, M.E. 2012. Species-specific

461 relationships between water transparency and male coloration within and between two closely related lake

462 victoria cichlid species. Int. J. Evol. Biol. 12-doi: 10.1155/2012/161306.

463 Crawley, M. 2002. Statistical computing: An introduction to data analysis using S-plus john wiley \& sons.

464 New York.

465 Crawley, M. 2007. The R Book-John wiley \& sons. Chichester, UK.

466 Cummings, M.E. 2007. Sensory trade-offs predict signal divergence in surfperch. Evolution 61: 530-545.

467 Endler, J.A. 1990. On the measurement and classification of colour in studies of animal colour patterns.

468 Biol. J. Linn. Soc. 41: 315-352.

469 Endler, J.A. 1992. Signals, signal conditions, and the direction of evolution. Am. Nat. 139: S125-S153.

470 Endler, J.A. \& Mappes, J. 2017. The current and future state of animal coloration research. Philos. Trans.

$471 \quad$ R. Soc. Lond. B. Biol. Sci. 372: 10.1098/rstb.2016.0352.

472 Fuller, R.C. \& Travis, J. 2004. Genetics, lighting environment, and heritable responses to lighting

473 environment affect male color morph expression in bluefin killifish, lucania goodei. Evolution 58: 1086-

4741098. 
475 Fuller, R.C. 2002. Lighting environment predicts the relative abundance of male colour morphs in bluefin

476 killifish (lucania goodei) populations. Proc. Biol. Sci. 269: 1457-1465.

477 Goldschmidt, T. 1991. Egg mimics in haplochromine cichlids (pisces, perciformes) from lake victoria.

478 Ethology 88: 177-190.

479 Haesler, M.P. \& Seehausen, O. 2005. Inheritance of female mating preference in a sympatric sibling

480 species pair of lake victoria cichlids: Implications for speciation. Proc. Biol. Sci. 272: 237-245.

481 Halekoh, U. \& Højsgaard, S. 2014. A kenward-roger approximation and parametric bootstrap methods for 482 tests in linear mixed models-the R package pbkrtest. J Stat Softw 59: 1-32.

483 Hornsby, M.A., Sabbah, S., Robertson, R.M. \& Hawryshyn, C.W. 2013. Modulation of environmental

484 light alters reception and production of visual signals in nile tilapia. J. Exp. Biol. 216: 3110-3122.

485 Hothorn, T., Bretz, F. \& Westfall, P. 2008. Simultaneous inference in general parametric models.

486 Biometrical journal 50: 346-363.

487 Kelley, J.L., Phillips, B., Cummins, G.H. \& Shand, J. 2012. Changes in the visual environment affect 488 colour signal brightness and shoaling behaviour in a freshwater fish. Anim. Behav. 83: 783-791.

489 Kenward, M.G. \& Roger, J.H. 1997. Small sample inference for fixed effects from restricted maximum 490 likelihood. Biometrics 53: 983-997.

491 Kenward, M.G. \& Roger, J.H. 2009. An improved approximation to the precision of fixed effects from 492 restricted maximum likelihood. Comput. Stat. Data Anal. 53: 2583-2595.

493 Kop, A. \& Durmaz, Y. 2008. The effect of synthetic and natural pigments on the colour of the cichlids

494 (cichlasoma severum sp., heckel 1840). Aquacult. Int. 16: 117-122. 
495 Lachlan, R. \& Servedio, M. 2004. Song learning accelerates allopatric speciation. Evolution 58: 20494962063.

497 Leclercq, E., Taylor, J.F. \& Migaud, H. 2010. Morphological skin colour changes in teleosts. Fish Fish. 498 11: 159-193.

499 Lewandowski, E. \& Boughman, J. 2008. Effects of genetics and light environment on colour expression in 500 threespine sticklebacks. Biol. J. Linn. Soc. 94: 663-673.

501 Lythgoe, J. 1968. Visual pigments and visual range underwater. Vision Res. 8: 997-1012.

502 Maan, M.E., Hofker, K.D., van Alphen, J.J. \& Seehausen, O. 2006. Sensory drive in cichlid speciation. 503 Am. Nat. 167: 947-954.

504 Maan, M.E. \& Seehausen, O. 2010. Mechanisms of species divergence through visual adaptation and 505 sexual selection: Perspectives from a cichlid model system. Curr Zool 56: 285-299.

506 Maan, M.E., Seehausen, O., Groothuis, T.G., Fuller, R.C. \& Bronstein, J.L. 2017. Differential survival

507 between visual environments supports a role of divergent sensory drive in cichlid fish speciation. Am. Nat.

508 189: 000-000.

509 Maan, M.E., Seehausen, O. \& Van Alphen, J.J. 2010. Female mating preferences and male coloration

510 covary with water transparency in a lake victoria cichlid fish. Biol. J. Linn. Soc. 99: 398-406.

511 Maan, M.E., Sefc, K.M. 2013. Colour Variation in Cichlid Fish: Developmental Mechanisms, Selective

512 Pressures and Evolutionary Consequences. Elsevier.

513 Magalhaes, I., Mwaiko, S., Schneider, M. \& Seehausen, O. 2009. Divergent selection and phenotypic

514 plasticity during incipient speciation in lake victoria cichlid fish. J. Evol. Biol. 22: 260-274. 
515 Magalhaes, I. \& Seehausen, O. 2010. Genetics of male nuptial colour divergence between sympatric sister

516 species of a lake victoria cichlid fish. J. Evol. Biol. 23: 914-924.

517 Mason, N.A., Burns, K.J., Tobias, J.A., Claramunt, S., Seddon, N. \& Derryberry, E.P. 2017. Song

518 evolution, speciation, and vocal learning in passerine birds. Evolution 71: 786-796.

519 McNeil, G.V., Friesen, C.N., Gray, S.M., Aldredge, A. \& Chapman, L.J. 2016. Male colour variation in a 520 eurytopic african cichlid: The role of diet and hypoxia. Biol. J. Linn. Soc. 118: 551-568.

521 Morrongiello, J., Bond, N., Crook, D. \& Wong, B. 2010. Nuptial coloration varies with ambient light 522 environment in a freshwater fish. J. Evol. Biol. 23: 2718-2725.

523 Nakagawa, S. \& Cuthill, I.C. 2007. Effect size, confidence interval and statistical significance: A practical 524 guide for biologists. Biol. Rev. 82: 591-605.

525 Pinheiro, J., Bates, D., DebRoy, S. \& Sarkar, D. 2014. R core team (2014) nlme: Linear and nonlinear 526 mixed effects models. R package version 3.1-117. Available at $h \mathrm{ttp}: / / C R A N . R$-project.org/package= 527 nlme.

528 Ripley, B., Venables, B., Bates, D.M., Hornik, K., Gebhardt, A., Firth, D. \& Ripley, M.B. 2015. Package

529 'MASS'. http://www.stats.ox.ac.uk/pub/MASS4/.

530 Sakamoto, Y., Ishiguro, M. \& Kitagawa, G. 1986. Akaike information criterion statistics. Dordrecht, The 531 Netherlands: D.Reidel.

532 Seehausen, O., Lippitsch, E., Bouton, N. \& Heleen, Z. 1998. Mbipi, the rock-dwelling cichlids of lake 533 victoria: Description of three new genera and fifteen new species (teleostei). Ichthyol. Explor. Freshwat. 534 9: 129-228. 
535 Seehausen, O. 1996. Lake Victoria Rock Cichlids: Taxonomy, Ecology, and Distribution. Verduyn

536 Cichlids, Germany.

537 Seehausen, O., Terai, Y., Magalhaes, I.S., Carleton, K.L., Mrosso, H.D., Miyagi, R., van der Sluijs, I., 538 Schneider, M.V., Maan, M.E. \& Tachida, H. 2008. Speciation through sensory drive in cichlid fish.

539 Nature 455: 620-626.

540 Seehausen, O. \& van Alphen, J.J. 1998. The effect of male coloration on female mate choice in closely

541 related lake victoria cichlids (haplochromis nyererei complex). Behav. Ecol. Sociobiol. 42: 1-8.

542 Seehausen, O., van Alphen, J.J. \& Witte, F. 1997. Cichlid fish diversity threatened by eutrophication that

543 curbs sexual selection. Science 277: 1808-1811.

544 Selz, O.M., Pierotti, M.E., Maan, M.E., Schmid, C. \& Seehausen, O. 2014. Female preference for male

545 color is necessary and sufficient for assortative mating in 2 cichlid sister species. Behav. Ecol. 25: 612546626.

547 Selz, O.M., Thommen, R., Pierotti, M.E., Anaya-Rojas, J.M. \& Seehausen, O. 2016. Differences in male

548 coloration are predicted by divergent sexual selection between populations of a cichlid fish. Proc. Biol.

549 Sci. 283: 10.1098/rspb.2016.0172.

550 Stelkens, R.B., Pierotti, M.E., Joyce, D.A., Smith, A.M., van der Sluijs, I. \& Seehausen, O. 2008.

551 Disruptive sexual selection on male nuptial coloration in an experimental hybrid population of cichlid fish.

552 Philos. Trans. R. Soc. Lond. B. Biol. Sci. 363: 2861-2870.

553 Stevens, M., PARraga, C.A., Cuthill, I.C., Partridge, J.C. \& Troscianko, T.S. 2007. Using digital

554 photography to study animal coloration. Biol. J. Linn. Soc. 90: 211-237. 
555 Sugimoto, M. 2002. Morphological color changes in fish: Regulation of pigment cell density and 556 morphology. Microsc. Res. Tech. 58: 496-503.

557 Theis, A., Roth, O., Cortesi, F., Ronco, F., Salzburger, W. \& Egger, B. 2017. Variation of anal fin egg558 spots along an environmental gradient in a haplochromine cichlid fish. Evolution.

559 Tobler, M. 2006. The eggspots of cichlids: Evolution through sensory exploitation. Zeitschrift für $560 \quad$ Fischkunde 8: 39-46.

561 van Alphen, J.J., Seehausen, O., Galis, F. 2004. Speciation and radiation in african haplochromine 562 cichlids. In: Adaptive Speciation (U. Dieckmann, M. Doebeli, J.A.J. Metz and D. Tautz, eds) . Cambridge 563 University Press, Cambridge, UK.

564 Witte-Maas, E. \& Witte, F. 1985. Haplochromis nyererei, a new cichlid fish from lake victoria named in 565 honour of mwalimu julius nyerere, president of tanzania. Brill, Leiden.

566 Wright, D., Demandt, N., Alkema, J., Seehausen, O., Groothuis, T. \& Maan, M. 2017. Developmental 567 effects of visual environment on species-assortative mating preferences in lake victoria cichlid fish. $J$. 568 Evol. Biol. 30: 289-299.

569 Zuur, A., Ieno, E., Walker, N., Saveliev, A. \& Smith, G. 2009. Mixed effects models and extensions in

570 ecology with R. gail M, krickeberg K, samet JM, tsiatis A, wong W, editors. New York, NY: Spring 571 Science and Business Media. 
Figure 1

Species colour differences

Species-specific scores for 'whole fish' coloration, expressed as principal components. Linear mixed modeling revealed significant species differences for PC1 (A), PC3 (C), and PC4 (D), but not for PC2 (B). Points represent individual PC scores, coloured as deep (orange) and shallow (light blue) rearing light. Error bars represent $95 \% \mathrm{Cl}$; indicates $\mathrm{P}<0.1, *$ indicates $\mathrm{P}<0.05$, **indicates $\mathrm{P}<0.01$, *** indicates $\mathrm{P}<0.001$. 
A)

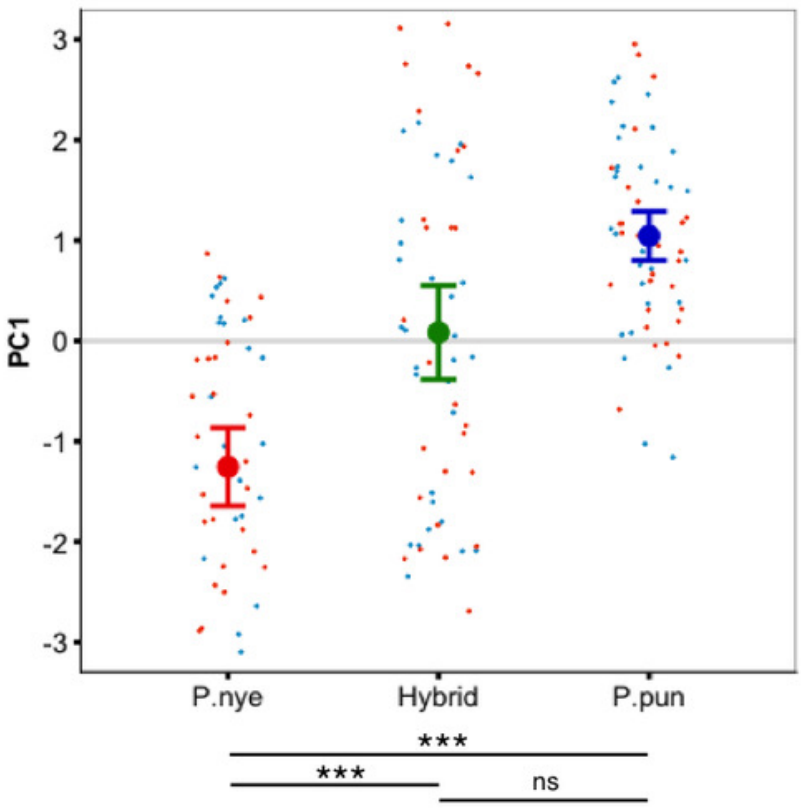

C)

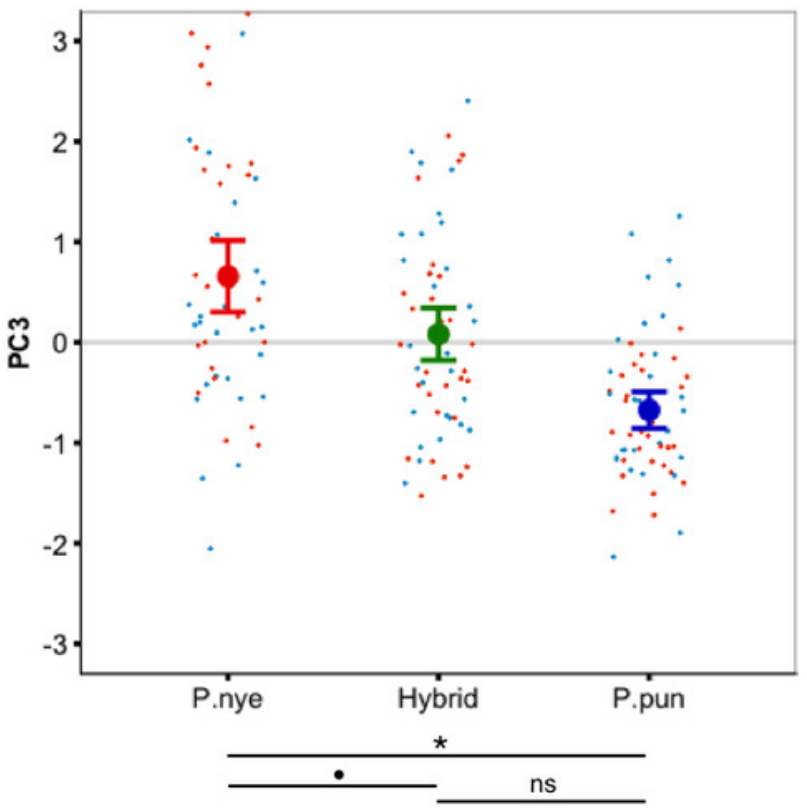

B)

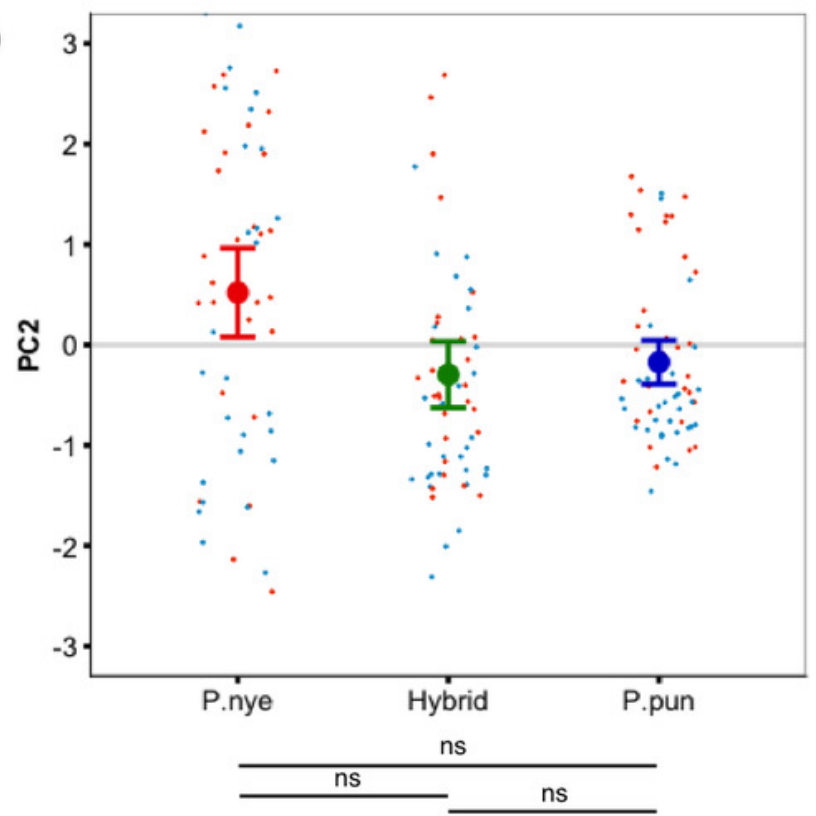

D)

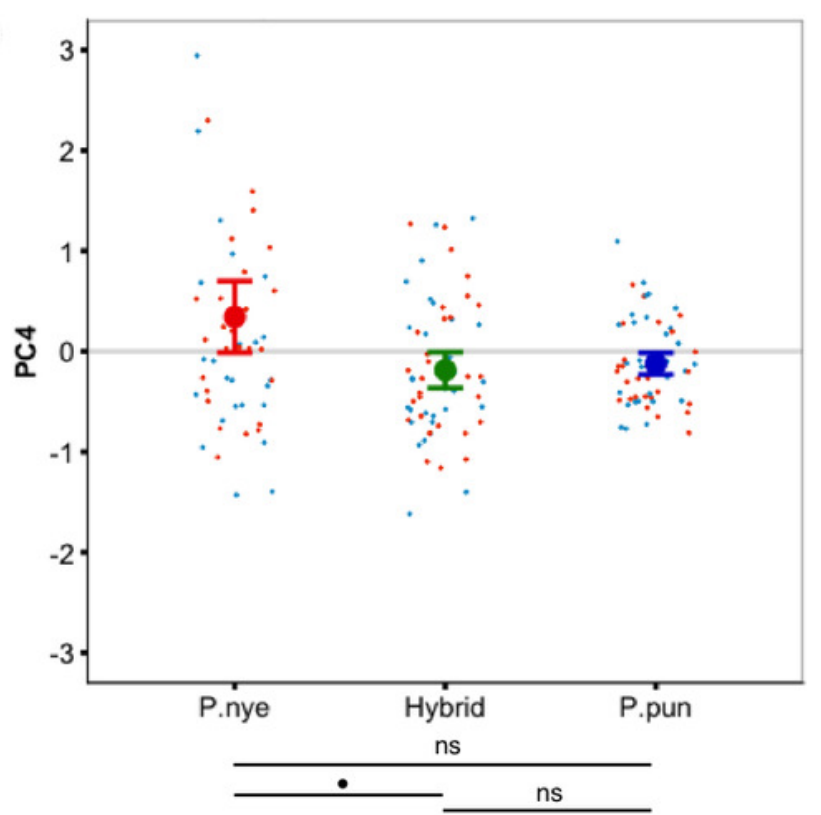




\section{Figure 2}

Species difference in anal fin spot number

$P$. nyererei had significantly more anal fin spots than $P$. pundamilia, while hybrids were intermediate and did not differ from either parental species. Error bars represent \pm one standard error, **indicates $\mathrm{P}<0.01$.

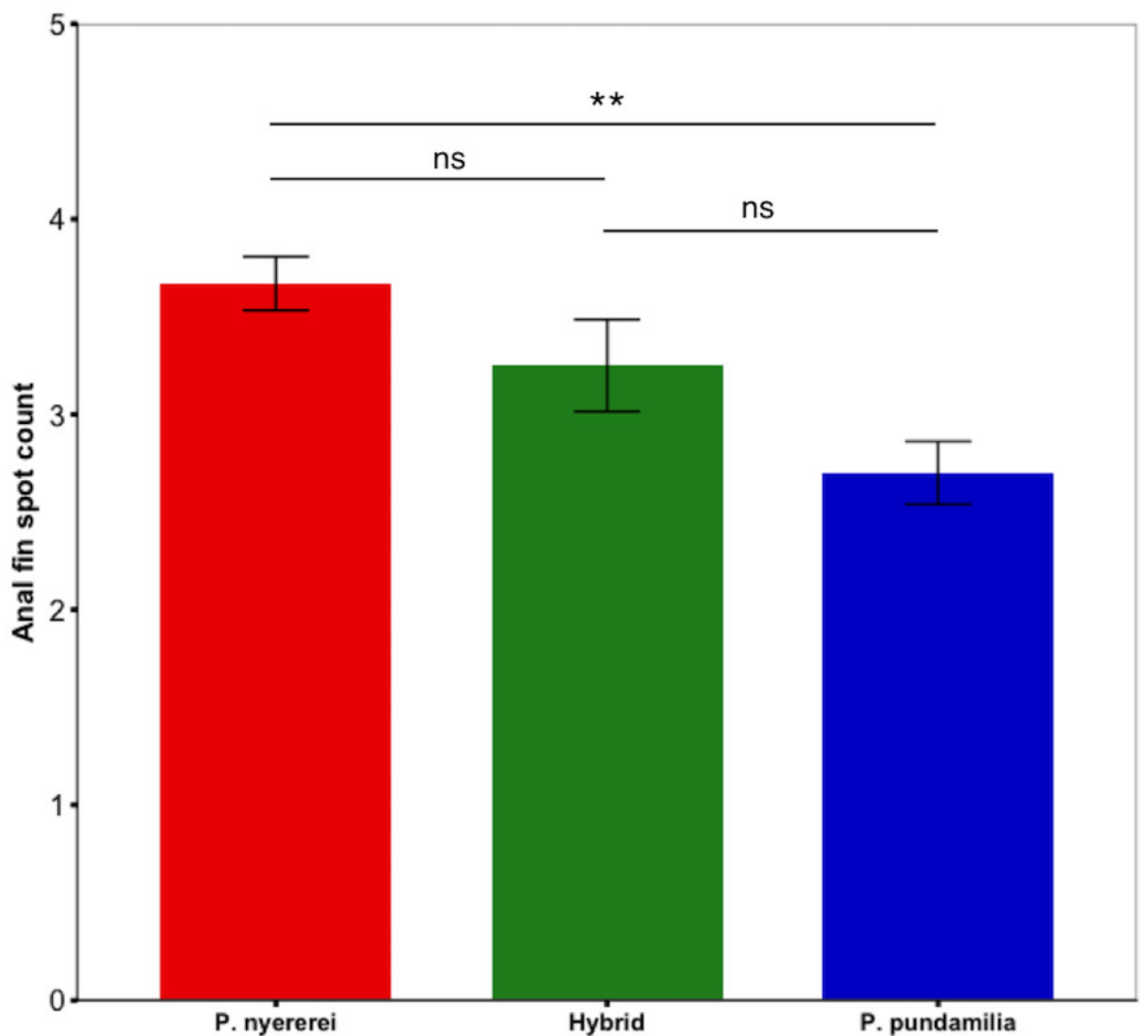


Figure 3

Deep-reared fish are greener

(A) Males reared in deep light differed significantly from their shallow-reared brothers in 'whole fish' PC2 scores. These differences could be attributed to the body (B) and, to a lesser extent, the caudal fin (C). Error bars represent $95 \% \mathrm{Cl}$, indicates $\mathrm{P}<0.1$, * indicates $\mathrm{P}<$ $0.05, * *$ indicates $\mathrm{P}<0.01$.

A)

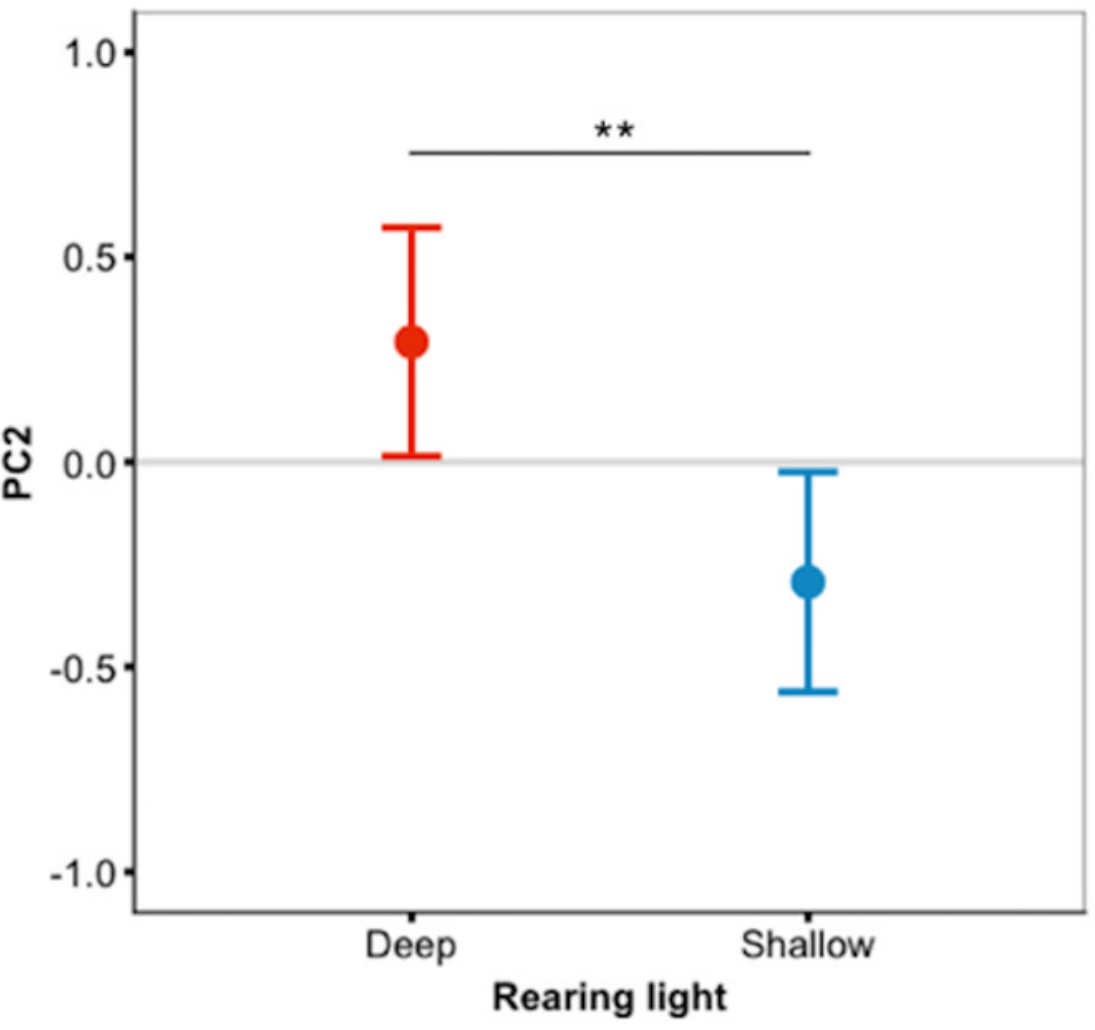

B)

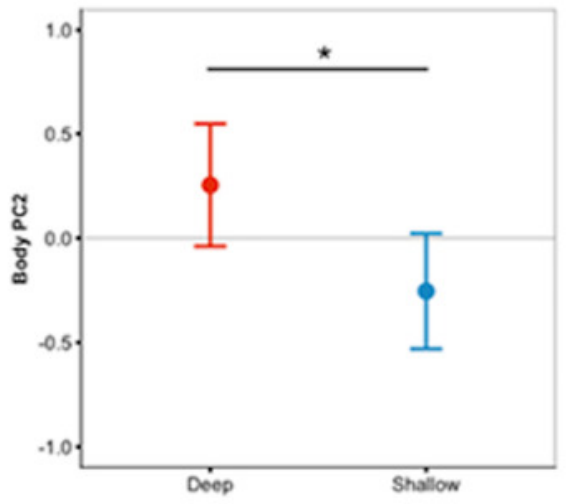

C)

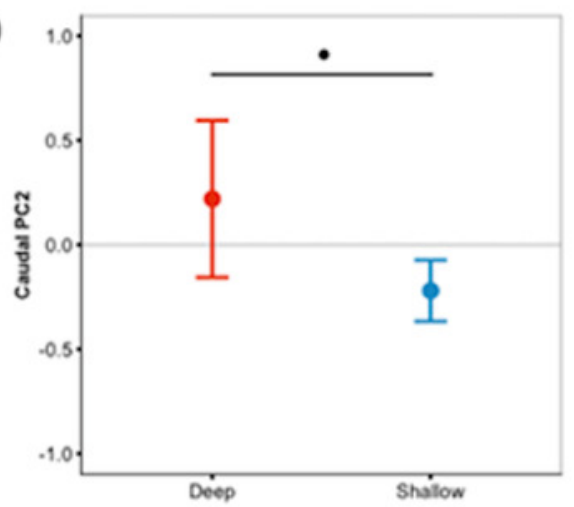




\section{Figure 4}

Treatment effect by colour category

Analyses of the individual colour scores confirmed the PCA results; (A) deep-reared fish were significantly greener than shallow-reared fish. No other colours differed significantly between rearing environments $(P>0.23$ for all). Error bars represent \pm one standard error, **indicates $\mathrm{P}<0.01$. (B) The deep and shallow light manipulations differed in the availability of shorter-wavelength light ( 400-550nm).
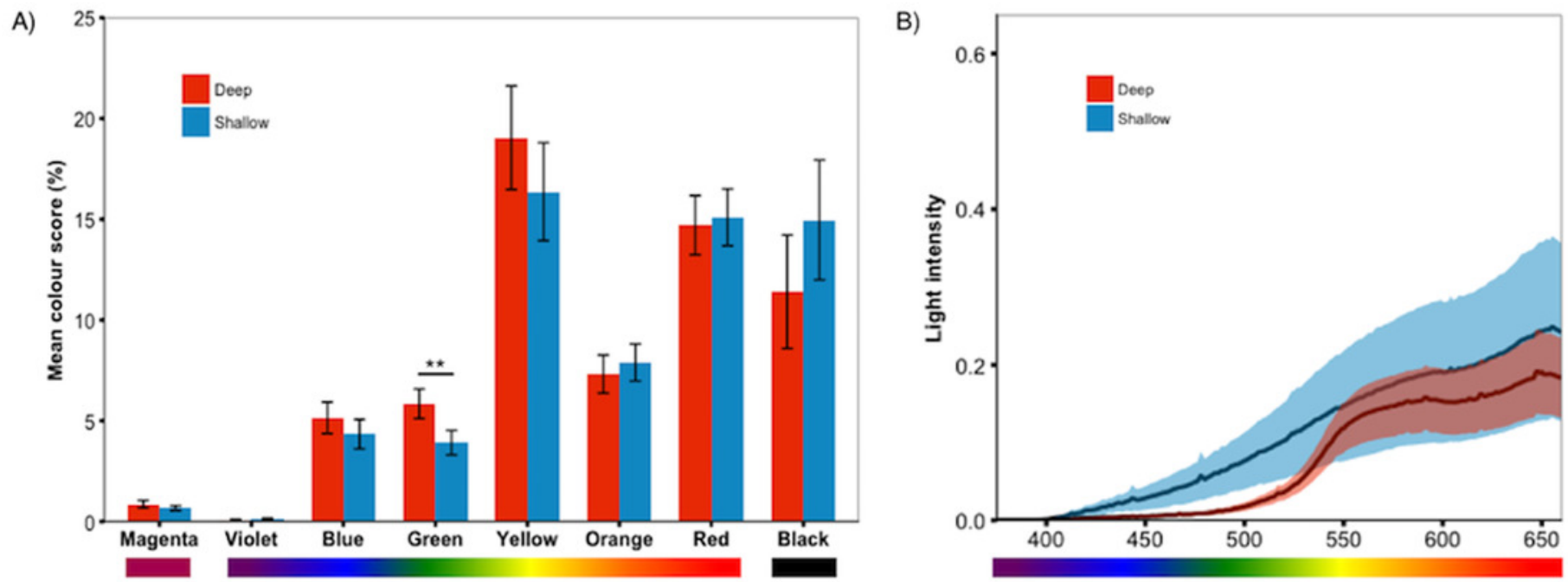
Figure 5

Little treatment-induced colour change in experiment 2

'Whole fish' PC scores of treatments groups (SD \& DS) displayed little difference from control groups ( $S S \& D D$ ) in experiment 2. PC scores are presented as the deviation from the mean (zero line) for each fish (3 samples each from experiment 1). Positive scores indicate an increase in PC scores, while negative indicate a decrease. Error bars represent $95 \% \mathrm{Cl}$.

A)

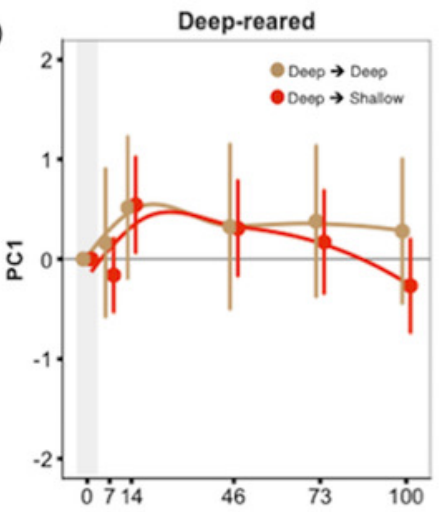

C)

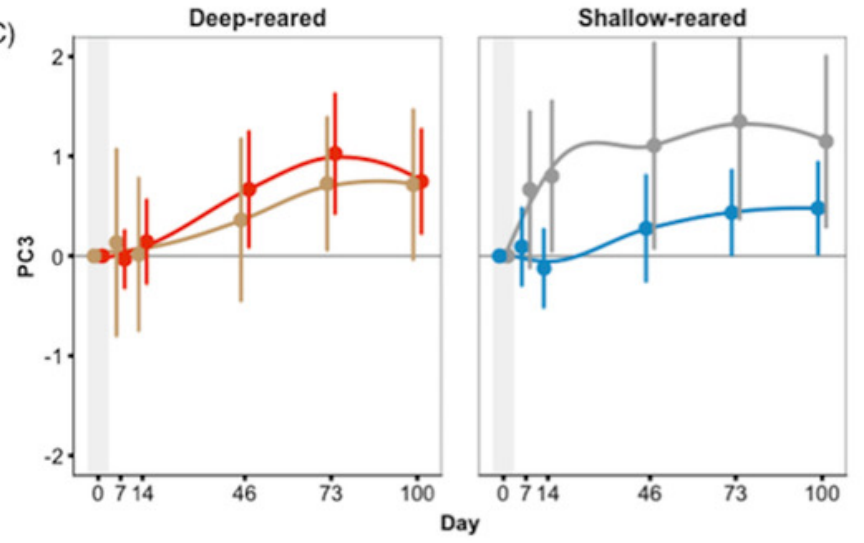

Shallow-reared

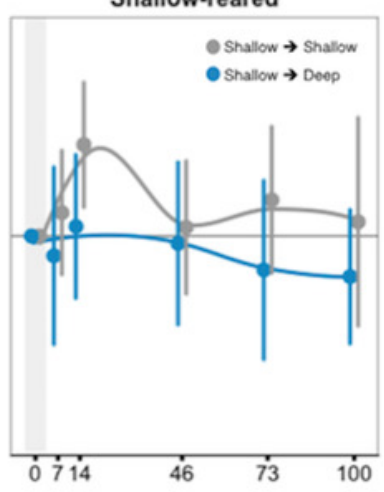

D)

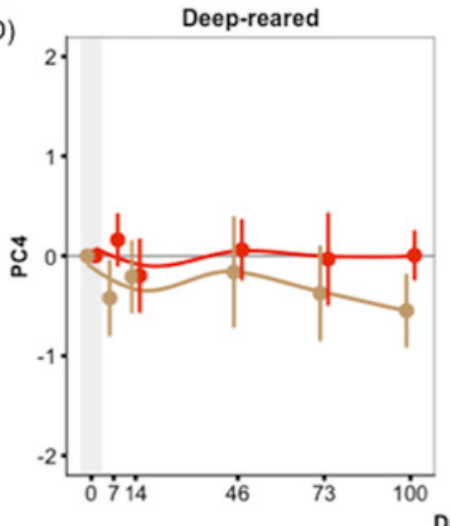

B)
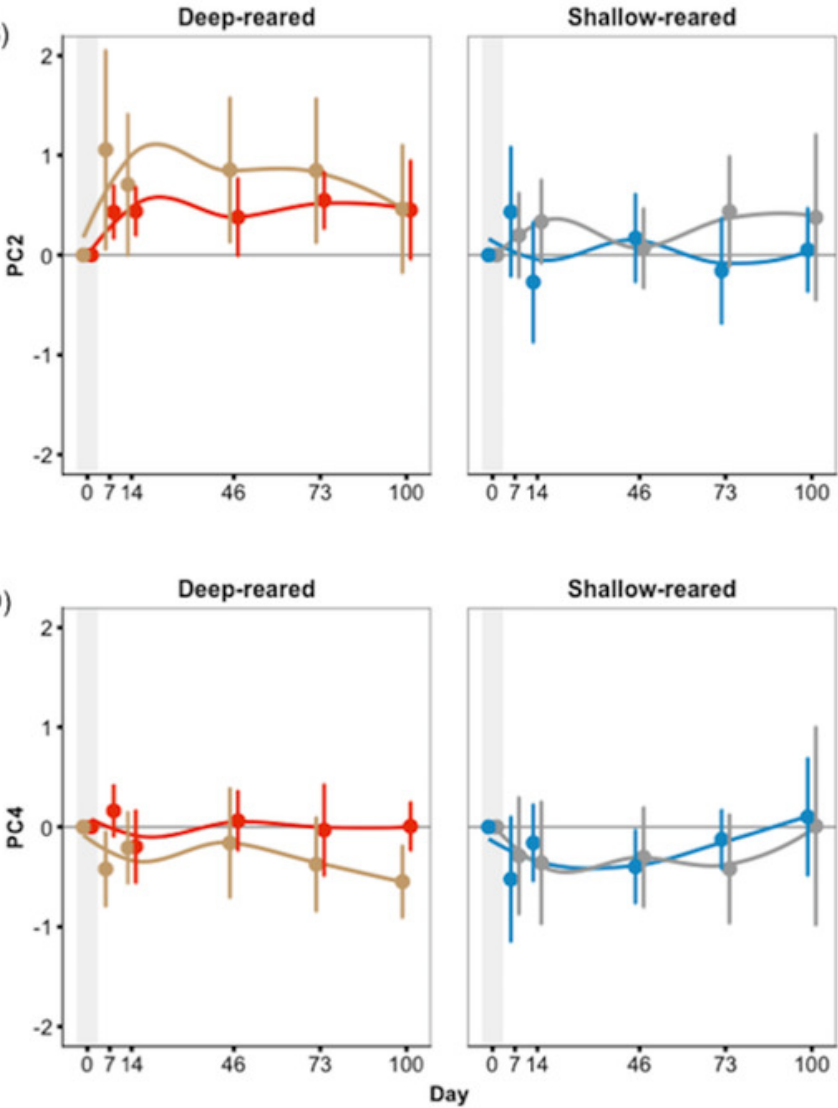